\title{
On the Importance of Gauge-Undercatch Correction Factors and Their Impacts on the Global Precipitation Estimates
}

\author{
${ }^{1}$ Mohammad Reza Ehsani, ${ }^{1,2}$ Ali Behrangi \\ ${ }^{1}$ The University of Arizona, Department of Hydrology and Atmospheric Sciences \\ 2 The University of Arizona, Department of Geosciences
}

Submitted to: Environmental Research Letters

\section{Corresponding author:}

Ali Behrangi, University of Arizona, Department of Hydrology and Atmospheric Sciences Mail:1133 E. James E Rogers Way, Harshbarger Rm. 226b, Tucson, AZ, 85721-0011. E-mail: Behrangi@email.arizona.edu

Keywords: gauge-undercatch, correction factors, global precipitation, GPCC, Legates, Fuchs 


\begin{abstract}
Precipitation gauges are critical for measuring precipitation rates at regional and global scales and are often used to adjust precipitation rates estimated from other instruments such as satellites. However, precipitation measured at the gauges is affected by gauge-undercatch that is often larger for solid precipitation. In the present work, two popular gauge-undercatch correction factors are assessed: one utilizes a dynamic correction model and is used in the Global Precipitation Climatology Centre (GPCC) Monitoring product and the other one employs a fixed climatology and is used in the Global Precipitation Climatology Project (GPCP) product. How much the choice of correction factors can impact the total estimate of precipitation was quantified over land at seasonal, annual, regional, and global scales. The correction factors are also compared as a function of the environmental variables used in their development, among those are near-surface air temperature, relative humidity, wind speed, elevation, and precipitation intensity. Results show that correction factors can increase the annual precipitation rate based on the gauges by $\sim 9.5 \%$ over the global land (excluding Antarctica), although this amount can vary from $\sim 6.3 \%$ (in boreal summer) to more than $10 \%$ (in boreal winter), depending on the season and the method used for gauge-undercatch correction. Annual variations of correction factors can also be large, so the use of the fixed climatology correction factors requires caution. Given their magnitudes and differences, selection of appropriate correction factors can have important implications in refining the water and energy budget calculations.
\end{abstract}




\section{1- Introduction}

Accurate spatiotemporal quantification of precipitation is crucial for scientific, commercial, and operational applications (Tapiador et al 2012, Kucera et al 2013, Kirschbaum et al 2017, Arabzadeh et al 2020). At the global scale, precipitation observations are often obtained from satellites or precipitation gauges, each offering its strengths and weaknesses (Adler et al 2003, Strangeways 2006, Becker et al 2013, Sun et al 2018). Satellites provide quasi-global coverage, but generally have relatively poor performance in capturing precipitation rate over snow and ice surfaces (Kidd et al 2012, Cao and Liang 2018, Behrangi et al 2018a, Levizzani et al 2011, Liu et al 2019b, 2019a, Skofronick-Jackson et al 2015, Adhikari et al 2020, Ehsani et al 2021, Vahedizade et al 2021, Bagaglini et al 2021, Duffy et al 2021, Yu et al 2020, Milani and Wood 2021). Precipitation gauges are critically important as they often serve as a reference to evaluate or develop other precipitation products. However, they often are (1) sparse, and (2) topographically biased towards lower altitudes in mountainous regions. In addition, the ability of a gauge to accurately measure precipitation varies as a function of the gauge characteristics, including the height and shape of the gauge, the orifice size, the material with which the gauge is constructed, and the presence or absence of a windshield (Adam and Lettenmaier 2003, Legates 1995, Legates and Bogart 2009).

Precipitation measurement errors can be divided into two main categories - systematic and unsystematic (random). Unsystematic errors include human error, such as inaccurate measuring and recording procedures. These errors can result in an increase or decrease in the amount of precipitation measured and they are difficult to correct. Systematic errors include site and location errors and how accurately gauge-catch approximates actual (true) precipitation. The main sources of systematic precipitation undercatch are due to deformation of the wind field above the gauge orifice, wetting losses due to water adhering to the inside of the gauge, evaporation, and sublimation of precipitation from the gauge before measurement, precipitation splashing in/out of the gauge, and the treatment of trace precipitation as zero. Together, these systematic biases mean that gauge-measured precipitation significantly underestimates actual precipitation. Although these biases are usually relatively small for liquid precipitation (4-10\%), they are much larger for solid precipitation and can exceed $90 \%$ of the total precipitation (Berkowitz and Balberg 1993, Yang et al 2005, 2000, 1999b, 2001, 1999a, Sevruk 1987, Sevruk and Klemm 1989, Sevruk et al 2009, Jimeno-Sáez et al 2020, Hirabayashi et al 2008, Grossi et al 2017, Groisman and Legates 1994, Goodison et al 1998, Fassnacht 2004, Cauteruccio et al 2020, Koehler 2019). Therefore, the use of appropriate correction methods to mitigate the precipitation undercatch can have a large impact on the accurate quantification of precipitation at regional and global scales.

Transfer functions are generally used to adjust for the undercatch of precipitation measurements. These functions are derived based on the variation of the collection efficiency with wind speed, precipitation intensity, and other determining factors for a particular type of gauge or multiple types of gauges, either using field experiments or based on numerical simulation (Sypka 2019, Pollock et al 2018, Fiser and Wilfert 2009, Colli et al 2018, 2020, 2015, Colli and Lanza 2016, Masuda et al 2019, Mekonnen et al 2015, Pierre et al 2019, Sugiura et al 2003).

Gridded precipitation products based on precipitation gauges have been corrected for systematic measurement errors using monthly and daily correction factors as discussed in Ungersböck et al. (2001). Two popular correction factors (CFs) currently used in global precipitation products are (1) Legates climatology (CF-L) utilized in the Global Precipitation Climatology Project (GPCP) (Adler et al 2018, 2003, Huffman et al 2020); and (2) Fuchs dynamic correction model (CF-F) 
used in the Global Precipitation Climatology Centre (GPCC) Monitoring product (Schneider et al 2014). Both GPCP and GPCC are commonly used by researchers for scientific analysis or the development of other precipitation products. For example, GPCP is used at a monthly scale to bias-adjust PERSIANN-CDR (Ashouri et al 2015) within $60^{\circ} \mathrm{S} / \mathrm{N}$, and to bias-adjust the Integrated Multi-satelliE Retrievals for GPM (IMERG) (Huffman et al 2020) over global land and high latitude oceans. GPCC is also widely used for global and regional water balance studies, calibration/validation of remote sensing-based rainfall estimations, and verification of numerical models (Nicholson et al 2003, Raziei et al 2010, 2011, 2015, Wang et al 2017a, 2017b, Basheer and Elagib 2019, Ajaaj et al 2016, Chen et al 2014, Prakash et al 2015, 2011, Sarmadi and Shokoohi 2015, Wei et al 2019). Therefore, it is important to carefully assess how the choice of CFs can affect these products.

Legates and Willmott (1990) found that precipitation gauge errors tend to be directly proportional to total precipitation and amount to nearly $11 \%$ of the global catch. They reported that an undercatch of less than 5\% occurs in the tropics, while more than $40 \%$ is common at the poles, illustrating the large influence of wind on undercatch of snowfall. Legates and Willmott (1990) developed the monthly correction factor (i.e., CF-L) to compensate for the systematic gaugemeasuring error. However, CF-L has several issues including but not limited to: (1) most of the observations collected between 1920 and 1980, and so the climatology is largely representative of those 60 years, (2) the type of gauges and their installation specifics were possibly obsolete in the early 1980s, and (2) assumptions used in the estimation of parameters (wind velocity, solid/liquid ratio, etc.) can lead to over-correction as high as $200 \%$ in some cases. Therefore, it seemed essential to determine and implement an improved correction method (Rubel and Hantel 2001a, 2001b, Rubel et al 2000).

Efforts such as (1) the development of a new catalog for standard precipitation gauges by the World Meteorological Organization (WMO) such as gauge types, windshield usage, and gauge rim height, (2) refinement of correction terms for evaporation and wetting errors, and (3) improvement of the daily precipitation intensity derivative algorithm from synoptic reports originally developed by Rubel and Hantel (1999), eventually led to another correction method commonly referred to as the Fuchs method (i.e., CF-F). CF-F uses the dynamic correction model (Rubel and Hantel 1999, Førland and Hanssen-Bauer 2000) and employs different synoptic observations such as near-surface air temperature $(\mathrm{T})$, relative humidity $(\mathrm{RH})$, precipitation rate (P), and wind speed (W). CF-F mainly exploit environmental variables for the determination of the precipitation phase (i.e., instead of air temperature alone, a combination of temperature and relative humidity has a much closer relation to precipitation phase) which is a very crucial point because the correction factors for liquid and solid precipitation differ significantly. CF-L and CFF methods are discussed in (Fuchs et al 2001, Legates and Willmott 1990).

Since precipitation gauges are often the only observational source for precipitation measurement, assessment of the CFs is very challenging. Projects such as the WMO Solid Precipitation Intercomparison Experiment (SPICE; 2013-2016) are valuable to assess bias-correction of precipitation gauges but they cover only limited areas and certain gauge types (Rasmussen et al 2012, Kochendorfer et al 2017, 2020, Smith et al 2020). By focusing on frozen regions in the northern hemisphere, Behrangi et al (2018b) used mass change observation from the Gravity Recovery and Climate Experiment (GRACE) to estimate monthly and seasonal snow accumulation through the water budget equation. They calculated snow accumulations from mass balance to assess CF-F and CF-L and found that CF-F is more consistent with the precipitation accumulations 
calculated using GRACE observations. Behrangi et al (2019) reported similar results by performing annual water budget analysis over several Arctic basins using streamflow observations. Although both studies suggested that CF-F is preferred over CF-L in most high latitude regions, Panahi and Behrangi (2020) showed that the use of CF-F may result in overestimation of snowfall over the northern part of the United States based on comparison with the University of Arizona Snow Water Equivalent (UA-SWE) product.

While additional studies are required to evaluate CFs in different regions, it is important to quantify how much the total precipitation estimates over land at annual, seasonal, regional, and global scales are affected by the choice of CFs. Also, environmental conditions that lead to larger differences in CFs should be investigated to better understand the relationship between CFs and synoptic variables. Present work attempts to address these questions. 


\section{2- Datasets and Methodology}

\section{2-1- GPCC Precipitation Products}

GPCC was established in 1989 at the request of the WMO. It is operated by Deutscher Wetterdienst (DWD, National Meteorological Service of Germany) and contributes to the World Climate Research Program (WCRP). GPCC provides gridded maps of monthly and daily precipitation over land (except Antarctica) based on in-situ rain gauges. In this study, the latest GPCC monthly Monitoring and Full data products (GPCC V2020; Zeise et al 2020; Schneider et al 2020) were used. Also, the previous version of the GPCC monthly Full data product (GPCC V2018; Schneider et al 2018) was used to assess changes in precipitation amount between the two versions. GPCC products are downloadable from https://opendata.dwd.de/climate environment/GPCC.

\section{2-2-1-Legates Correction Factor (CF-L)}

Using traditional land-based gauge measurements and shipboard estimates, Legates and Willmott (1990), developed a global climatology of mean monthly precipitation. The dataset includes 24,635 spatially independent terrestrial station records and 2,223 oceanic grid-point records from 1920 to 1980. Legates' method can be used to correct gauge-induced biases and remove systematic measurement errors because of wind on the inner walls of the gauge and gauge evaporation. Legates corrected monthly precipitation records were interpolated with a spherically based interpolation algorithm. Monthly CF-Ls based on long-term (1920-1980) mean precipitation data are available at $1^{\circ} \times 1^{\circ}$ degree resolution a at $10 \times 10$ degree resolution $t$ https://opendata.dwd.de/climate_environment/GPCC/legates/.

\section{2-2-2- Fuchs Correction Factor $(C F-F)$}

Fuchs's correction method is based on a dynamic correction model, explained by (Rubel and Hantel 1999, Førland and Hanssen-Bauer 2000), originally developed for gauges in European countries that participated in the Baltic Sea Experiment (BALTEX) of the Global Energy and Water Cycle Experiment (GEWEX). The method uses synoptic observation of environmental variables (i.e., wind speed at the rim of the gauge, air temperature, relative humidity, and precipitation phase and intensity) to calculate daily corrections. The daily corrections include wind-induced losses and climatological correction for evaporation and wetting loss (Ungersböck et al 2001, Fuchs et al 2001). An important step in the Fuchs correction method was improving the phase of precipitation events that could be determined by using appropriate data obtained from synoptic reports that are regularly exchanged through the WMO Global Telecommunication System (GTS). The method uses a combination of surface air temperature and relative humidity, instead of temperature alone, to improve phase separation that can lead to a more realistic bias-correction procedure for precipitation events. The Fuchs CFs are provided as a field in the GPCC monthly Monitoring product.

During the analysis, we noticed that some of the monthly CF-F data provided by GPCC have missing values. Figure S1 depicts the time-series of missing values as a percentage of total land grids, and the location of missing grids. The missing values are less than $1.5 \%$ of the total land grids. While these missing grids occur mainly during 2007-2011, they were removed from the entire record for consistency of calculations. 


\section{2-3- ERA5 Global Reanalysis}

ERA5 is the latest generation of European Center for Medium-range Weather Forecasting (ECMWF) atmospheric reanalysis. ERA5 is available from 1950 onward and is a replacement for the ERA-interim reanalysis product. It uses 4D-Var data assimilation using Cycle 41r2 of the Integrated Forecasting System (IFS). In the present work, synoptic variables at $0.25^{\circ}$ spatial resolution were obtained from https://cds.climate.copernicus.eu/cdsapp\#!/dataset/reanalysis-era5single-levels-monthly-means.

\section{2-4- Methodology}

CF-Fs were obtained from the GPCC Monitoring product at $1^{\circ} \times 1^{\circ}$ degree resolution for each month for the period of study (i.e., 1982-2019). CF-Ls constant monthly CFs were compared to dynamic monthly CF-F, geographically and zonally, and separately for all seasons and several regions. Also, annual, and seasonal mean precipitation rates using the two correction methods were quantified and compared on a global scale and for several regions. In addition, synoptic variables (i.e., T, RH, W) from ERA5 were used to analyze CFs and their differences in relations to environmental conditions by comparing CFs as a function of elevation (E), T, RH, W, and precipitation rate $(\mathrm{P})$. Also, CFs and their differences were studied as a function joint distribution of synoptic variables. The analyses were performed only over continental land areas, where both CFs are available. All of the products were mapped onto a common $1^{\circ} \times 1^{\circ}$ degree resolution grids prior to the analysis. 


\section{3- Results \& Discussions}

To investigate how CFs change with latitude, the zonal average of CF-F and CF-L for each season were calculated as shown in Figure 1. Since CF-L is constant for each month, seasonal mean values are shown with a line (shown in blue). On the other hand, CF-F is dynamic, thus, in addition to the long-term mean (orange line), variations for each latitude within the period of study (i.e., 19822019) are shown with orange shaded areas.

Figure 1 shows that within $45^{\circ} \mathrm{S} / \mathrm{N}$ in all seasons, (1) there is a good agreement between both $\mathrm{CFs}$, (2) the zonal averages of CF-F and CF-L almost overlap, and (3) variation of CF-F is relatively small. The relative difference (i.e., $\frac{100 \times C F-F}{C F-L}$ ) plot (Figure $2 \mathrm{a}$ ) also confirms the consistency of CFs within $45^{\circ} \mathrm{S} / \mathrm{N}$. CF-F provides larger CFs compared to CF-L poleward of $60^{\circ} \mathrm{N}$ in DJF, MAM, and SON with relative differences exceeding $30 \%$ in winter. On the other hand, CF-L seems to have larger values poleward of $50^{\circ} \mathrm{S}$ in the southern hemisphere for all seasons except JJA. Figure 1 also indicates that the variability of CF-F is much larger poleward of $30^{\circ} \mathrm{S}$ and $60^{\circ} \mathrm{N}$ in all seasons. In other words, in higher latitudes, variation of CF-F can be very large across different years, but this annual variation is missed when constant CF-L climatology is used. These observations indicate that (1) in mid and low latitudes, the undercatch issue is small whereas near the poles large corrections factors are common, (2) the undercatch is often larger for solid precipitation which is in line with previous studies (Legates 1995, Legates and Bogart 2009), (3) using constant CFs (i.e., CF-L) does not provide any information about annual variability, and (4) the greatest biases are likely to occur in high altitude sites, where snowfall is common.

Although Figure 1 is insightful for investigating the overall relationship between CFs, zonal averages can be misleading. In other words, when regional differences in CFs are averaged at each zone, there might be a cancelation effect. Therefore, it will be informative to assess the spatial distribution of CFs and their relative differences. Geographic maps of the average seasonal CFs are shown in Figure 3, separately for CF-F and CF-L. In addition, the relative differences between these two CFs (i.e., $\frac{100 \times C F-F}{C F-L}$ ) are plotted for all seasons. Figure 3 indicates large regional variations in CFs that could not be fully explored in the zonal plots. Both CF-F and CF-L report larger CFs for DJF, MAM, and SON compared to JJA in NH.

Scrutinizing seasonal relative differences of the CF-F and CF-L reveals that CF-F provides larger CFs in North America and Alaska (except for the coastal regions where precipitation rates are usually higher), parts of Greenland, and scattered regions in Siberia, Himalaya, South America, Australia, and parts of Africa in DFJ, MAM, and SON. On the other hand, CF-L is larger in Northern Europe, parts of Asia, and coastal regions in North America. In other parts of the world, the relative differences between the $\mathrm{CFs}$ lie within \pm 5 percent in all seasons. In higher latitudes, the relative difference can exceed 50\% in several regions suggesting that (1) the choice of CF can have a significant impact in estimating the actual amount of precipitation, and (2) the undercatch is often larger for snowfall than rainfall.

Figure 3 also indicates that (1) over large areas in Canada, CF-L is about one, while CF-F shows values larger than one that is expected; however, in coastal regions that often have higher precipitation rates CF-L provides larger CFs, (2) over the northern part of the United States, CF-F is larger than CF-L in all seasons except summer. This is also consistent with Panahi and Behrangi (2020) in which they found that in very cold conditions, the use of CF-F may result in 
overestimation of snowfall accumulation, and (3) over Eurasia and especially in winter, CF-L is considerably larger than CF-F. Mass change analysis using GRACE observations as well as net surface water exchange analysis suggest that CF-L is likely too high over this region (Behrangi et al 2014; 2018b, 2019).

Due to the large regional differences observed between CFs, seven regions (shown in Figure 4) were defined to further investigate the impacts of CFs on the regional mean precipitation rates. These regions include Canada and Alaska, the US, Greenland, Tropics, Eurasia, Siberia and Himalaya, and higher latitudes in the southern hemisphere (hereafter $\mathrm{HSH}$ ). To quantify the impact of CFs on precipitation estimates at both global and regional scales, CFs were applied to GPCC V2020, and monthly mean precipitation rates were calculated for the global land (except Antarctica) and seven regions defined in Figure 4. Figure 5 shows seasonal time-series of mean monthly GPCC, GPCC after applying CF-L (GPCC-L), and GPCC after applying CF-F (GPCCF) for the global land, US, HSH, and Eurasia. Note that the time-series represents monthly mean values, but the reported unit in Figure 5 is $\mathrm{mm}$ /day. In addition to the absolute values, relative differences of GPCC-L and GPCC-F with respect to GPCC (i.e., $\frac{G P C-F}{G P C C}$ and $\frac{G P C C-L}{G P C C}$ ) are also plotted in separate panels for each region with the trendlines showing how they evolve in time.

Time-series of the global mean precipitation rate indicate that choosing CF-L over CF-F leads to higher mean global precipitation rates (Figure 5a). Over the US, the use of CF-F leads to larger values in DJF and larger variations compared to that obtained by using CF-L (Figure 5b), which was also observed in Figure 3. In Eurasia (Figure 5c), CF-L provides larger mean daily precipitation rates, which is consistent with Figure 3. Similar plots are provided for four other regions in the supplementary materials (Figure S2).

Figure 5a indicates that there is an increasing trend in the global mean GPCC-F, especially from 1982 to 2000, while GPCC-L does not show any obvious trend (the slope of the GPCC-F trendline is $\sim 16$ times larger than that of GPCC-L). A similar trend can be observed over SHS where the slope of GPCC-F is $\sim 16$ times larger than that of GPCC-L. These trends in GPCC-F can be related to its dynamic nature which can be affected by the change in environmental conditions (e.g., T, $\mathrm{RH}$, and W). On the other hand, the static nature of CF-L does not necessarily follow trends in climate variables [climate variables show trends due to climate change and global warming in the past two decades; (Ehsani et al 2020)].

Investigating the monthly global T, RH, and W using ERA5 (Figure S3), shows an increasing trend in $\mathrm{T}$, decreasing trend in $\mathrm{RH}$, and increasing trend in $\mathrm{W}$ that may partly explain the global increase in GPCC-F. However, it is important to note that CF-F is calculated using synoptic station data, so the analysis using ERA5 may not be fully representative. Interestingly, the global trend in GPCC-F is similar to that observed in HSH (Figure 5c), and the trend in SHS is consistent with the corresponding time-series of $\mathrm{T}, \mathrm{RH}$, and $\mathrm{W}$ (Figure S3). This observation suggests that understanding the changes in GPCC-F requires a more detailed analysis of synoptic data that could be a topic for future investigations.

Quantifying how much the choice of CFs can impact the "measured precipitation" amount is very important, at least from the perspective of Earth's water and energy budget analysis. Gaugedependent bias-correction of conventional observed precipitation is essential before using these analyses for calibration of remote-sensing data, for verification of model results, for water balance assessments as well as for climate change studies (Fuchs et al 2001). Table 1 shows the annual 
and seasonal global mean precipitation rates over land (excluding Antarctica) from GPCC V2020, GPCC-L, GPCC-F, and GPCC V2018. The values in parentheses display the percent change in total precipitation compared to GPCC V2020 that has no gauge undercatch correction. The results indicate that at the annual scale, using CF-L leads to a 9.5\% increase in mean global daily precipitation rate while CF-F increases this value by $6.3 \%$. The analysis also indicates that there is only a slight difference between GPCC V2020 and GPCC V2018 at a global scale with a maximum difference of no more than $0.2 \%$ in DJF. Seasonal values of GPCC-L and GPCC-F indicate that both CF-L and CF-F result in the largest increase in precipitation rates in DJF and the least increase in JJA, which is consistent with Figure 3.

The increase in precipitation rate due to applying CFs is relatively large. Previous studies have suggested that the global precipitation rate obtained from GPCP (that uses CF-L to correct GPCC) needs to be increased by $\sim 5 \%$ (Trenberth et al 2009, Rodell et al 2015, 2015, 2005, 2004) or higher (Stephens et al 2012) to bring water and energy budget into balance. Therefore, even though here the analysis is only over land, the large increase in GPCC precipitation rates by applying CFs and the relatively large differences between GPCC-L and GPCC-F suggest that the choice of CFs can significantly impact the understanding of the Earth system processes at regional and global scales. As an example, precise knowledge of surface energy fluxes profoundly affects our ability to understand how Earth's climate responds to increasing concentrations of greenhouse gases. Note that by using CF-F, the annual increase in GPCC precipitation can be $\sim 3.2 \%$ less than that suggested by CF-L over land. Since CF-F has a dynamic nature that utilizes synoptic variables, it might provide a more accurate estimate of the global precipitation rate (Schneider et al. 2017). However, studies have shown that the accuracy of CF-F and CF-L can be regionally dependent (Behrangi et al. 2018b, 2019; Panahi and Behrangi et al. 2020). Mean annual and seasonal precipitation changes in the seven regions identified in this study were also investigated (Figure S4). The results indicate that the increase in mean precipitation rate due to applying CFs is largest in Greenland (i.e., $\sim 40 \%$ annually and more than $60 \%$ in DJF) and smallest in the tropics (i.e., $\sim 5 \%$ or less) which emphasize the importance of using CFs for higher latitudes.

As discussed earlier, CF-F and CF-L are different from each other in utilizing environmental variables, among those are $\mathrm{T}, \mathrm{RH}, \mathrm{W}, \mathrm{E}$, and $\mathrm{P}$. In addition to the analysis of regional differences between the CFs, it is important to investigate how CFs differ as a function of these environmental variables. Figure 6 shows the average values of CF-F and CF-L, and their relative differences, as a function of T, RH, W, E, and P. Sample counts in each bin are also shown in adjacent panels. Figure 6 demonstrates that as T decreases, both CF-F and CF-L tend to increase, but for colder temperatures (less than $0{ }^{\circ} \mathrm{C}$ ), CF-L remains almost constant (Figure 6a). This behavior can justify why $\mathrm{CF}-\mathrm{F}$ has larger values at very high latitudes and very cold regions in the northern CONUS (Figure 1). CF-F exceeds CF-L by $\sim 20 \%$ for $\mathrm{T}$ less than $0{ }^{\circ} \mathrm{C}$, while at warmer T, CF-L and CF-F are comparable.

CFs increase while RH is less than $\sim 80 \%$, at which both CFs show their maximum values (Figure 6c). While CF-F is slightly higher than CF-L for RH less than $80 \%$ and lower than CF-L for RH higher than $80 \%$, both CFs show a similar relationship to RH. As W increases, both CF-L and CF$\mathrm{F}$ tend to increase up to $7 \mathrm{~m} \mathrm{~s}^{-1}$ and then decrease at high wind speed (e.g., greater than $10 \mathrm{~m} \mathrm{~s}^{-1}$; Figure 6e). While it is not clear why at high wind speed CFs are smaller, the number of samples is lower for $\mathrm{W}$ greater than $10 \mathrm{~m} \cdot \mathrm{s}^{-1}$ that may affect the results (Figure 6f). In general, CF-F is larger for wind speeds between 4 and $10 \mathrm{~m} \mathrm{~s}^{-1}$, while CF-L is larger at higher wind speeds. 
Both CF-F and CF-L show similar behavior as a function of precipitation rates, except for very low precipitation rates. As $\mathrm{P}$ increases, CFs tend to show smaller numbers (Figure 6g). This could be due to: (1) larger CFs are needed for light precipitation rate as they can be more easily moved away from the gauge inlet, (2) lighter precipitation occurs in higher latitudes where snowfall is more common. Nonetheless, the behavior of CF-F and CF-L are consistent regarding the change in $\mathrm{P}$. In terms of elevation, both CFs increase with elevation up to $\sim 3,000 \mathrm{~m}$ and decrease in higher altitudes (Figure 6i). CF-F provides larger values in elevations lower than 3,000 $\mathrm{m}$. While this might be related to the fact that gauges are usually located at altitudes lower than $3,000 \mathrm{~m}$, there is no clear insight in support of the observed relationship at higher altitudes. Furthermore, CF-F tends to have larger values than CF-L, especially at higher elevations. To summarize, Figure 6 shows that the difference between CFs in different regions can be traced through environmental conditions in which they behave differently. However, commenting on their behavior as a function of only a single environment variable can be inaccurate. Therefore, it is valuable to analyze CFs as a function of two or more variables.

To further investigate the impact of environmental conditions on CFs, average CFs and their relative differences (i.e., $\frac{100 \times C F-F}{C F-L}$ ) are plotted for the joint distribution of T, RH, W, E, and P (Figure 7). Figure 7 is insightful as it can provide additional information on the specific environmental conditions that lead to major differences between CF-L and CF. For example, based on Figure 7, it can be stated that: (1) CFs are larger for higher $\mathrm{W}$ and lower $\mathrm{T}$ and CF-F provides larger values in such conditions, (2) CF-F is larger than CF-L for lower T and lower $\mathrm{P}$ (which is typical of high latitude and snowfall events) and also lower $\mathrm{T}$ and intense precipitation events, and (3) CF-F is larger for mild precipitation events and W within 5 to $10 \mathrm{~m} / \mathrm{s}-1$. These are examples of environmental conditions that lead to different behavior in CFs; however, this topic needs to be investigated in more detail in future studies. 


\section{4- Concluding Remarks}

Accurate estimation of precipitation amount and distribution is critical for regional and global studies. Over land, precipitation gauges provide measurements of precipitation rate and through interpolation, precipitation rate can be estimated at the regional and global scale. Precipitation measurements at gauges are also critical for correction of satellite precipitation retrievals, thus most of the gridded satellite-based precipitation products tend to produce a satellite-gauge product to improve their retrieval biases using precipitation measurements at rain gauges. However, it is important to realize that precipitation measurements at rain gauges also face errors due to gaugeundercatch.

In the present study, two popular gauge-undercatch CFs were investigated: (1) CF-L used in GPCP, and (2) CF-F used in GPCC Monitoring product. CF-L is based on the climatology of monthly precipitation records from 1920-1980 and is available as monthly maps of correction factors that are constant and do not change from one year to another. In contrast, CF-F is based on a dynamic correction model that uses synoptic observation of environmental variables (e.g., wind speed at the rim of the gauge, air temperature, relative humidity, and precipitation intensity and phase) to calculate daily CFs. The extent that the choice of the CFs can impact the total estimate of precipitation over land was quantified at seasonal, annual, regional, and global scales and CFs were related to major environmental variables (i.e., near-surface T, RH, W).

Both CFs are larger in higher latitudes, and CF-F exceeds CF-L poleward of $\sim 60{ }^{\circ} \mathrm{N}$ in all seasons. At around $70{ }^{\circ} \mathrm{N}$ in winter, the mean CF-F reaches its maximum value, suggesting a more than $100 \%$ increase in the measured precipitation intensity (Figure 1a). In lower latitudes (i.e., $45^{\circ} \mathrm{S}$ $45^{\circ} \mathrm{N}$ ); however, the relative differences between zonally averaged CF-F and CF-L often stay within $\pm 5 \%$, partly because CFs are much smaller for rainfall than snowfall and are directly proportional to the total precipitation.

Regional assessment of CFs, through geographical maps, reveals additional information and is less prone to the cancelation issue that affects zonal plots. Despite their overall consistency, CF-F and CF-L show large regional differences, among those are the northern part of the Central United States (where CF-F can be much larger than CF-L in all seasons except summer) and Eurasia (where CF-L is considerably larger than CF-F), especially in winter. It was also found that CF-L tends to be larger than CF-F in some coastal regions, where precipitation rates are large (e.g., the coastal region of the Gulf of Alaska), which can significantly affect the regional or continental precipitation rates.

Over global land (except Antarctica), the use of CF-L and CF-F results in an increase of the latest GPCC Full product (V2020) by $9.5 \%$ and $6.3 \%$, respectively. This increase is largest during boreal winter $(10.3 \%$ for CF-L and $6.7 \%$ for CF-F) and smallest during boreal summer $(8.0 \%$ for CF-L and $5.8 \%$ for CF-F). This increase in precipitation is fairly large and suggests that the choice of CFs can have considerable impacts on the water and energy budget calculations. Since CF-F has a dynamic nature and utilizes synoptic variables, it might provide a more accurate estimate of the global precipitation rate. However, studies have shown that the accuracy of CF-F and CF-L can be regionally dependent.

The analysis presented here suggests that further efforts are needed to reduce gauge undercatch errors (e.g., through the installation of more accurate gauges or the development of improved 
methods to correct their undercatch). Furthermore, it is important to understand how changes in CFs might be affected by the quality and stability of synoptic data, a topic for future investigations. 


\section{Acknowledgments}

The research described in this paper was carried out at the University of Arizona. Financial support for the University of Arizona is made available partly from NASA MEaSUREs (NNH17ZDA001N-MEASURES) and NASA Weather and Atmospheric Dynamics (NNH19ZDA001N-ATDM) awards. 


\section{References}

- Adam J C and Lettenmaier D P 2003 Adjustment of global gridded precipitation for systematic bias J. Geophys. Res. Atmos. 108 1-15

- Adhikari A, Ehsani M R, Song Y and Behrangi A 2020 Comparative Assessment of Snowfall Retrieval From Microwave Humidity Sounders Using Machine Learning Methods Earth Sp. Sci. 7 Online: https://onlinelibrary.wiley.com/doi/10.1029/2020EA001357

- Adler R F, Huffman G J, Chang A, Ferraro R, Xie P-P P, Janowiak J, Rudolf B, Schneider U, Curtis S, Bolvin D, Gruber A, Susskind J, Arkin P and Nelkin E 2003 The Version-2 Global Precipitation Climatology Project (GPCP) Monthly Precipitation Analysis (1979-Present) J. Hydrometeorol. 4 1147-67 Online: http://journals.ametsoc.org/doi/10.1175/15257541(2003)004\%3C1147:TVGPCP\%3E2.0.CO;2

- Adler R F, Sapiano M R P, Huffman G J, Wang J J, Gu G, Bolvin D, Chiu L, Schneider U, Becker A, Nelkin E, Xie P, Ferraro R and Shin D Bin 2018 The Global Precipitation Climatology Project (GPCP) monthly analysis (New Version 2.3) and a review of 2017 global precipitation Atmosphere (Basel). 9

- Ajaaj A A, Mishra A K and Khan A A 2016 Comparison of BIAS correction techniques for GPCC rainfall data in semi-arid climate Stoch. Environ. Res. Risk Assess. 30 1659-75

- Arabzadeh A, Ehsani M R, Guan B, Heflin S and Behrangi A 2020 Global Intercomparison of Atmospheric Rivers Precipitation in Remote Sensing and Reanalysis Products J. Geophys. Res. Atmos. 125 Online: https://onlinelibrary.wiley.com/doi/10.1029/2020JD033021

- Ashouri H, Hsu K L, Sorooshian S, Braithwaite D K, Knapp K R, Cecil L D, Nelson B R and Prat O P 2015 PERSIANN-CDR: Daily precipitation climate data record from multisatellite observations for hydrological and climate studies Bull. Am. Meteorol. Soc. 96 69-83

- Bagaglini L, Sanò P, Casella D and Cattani E 2021 Algorithm for Climate Applications (PNPRCLIM): Design and Verification

- Basheer M and Elagib N A 2019 Performance of satellite-based and GPCC 7.0 rainfall products in an extremely data-scarce country in the Nile Basin Atmos. Res. 215 128-40 Online: https://doi.org/10.1016/j.atmosres.2018.08.028

- Becker A, Finger P, Meyer-Christoffer A, Rudolf B, Schamm K, Schneider U and Ziese M 2013 A description of the global land-surface precipitation data products of the Global Precipitation Climatology Centre with sample applications including centennial (trend) analysis from 1901present Earth Syst. Sci. Data 5 71-99 Online: https://essd.copernicus.org/articles/5/71/2013/

- Behrangi A, Bormann K J and Painter T H 2018a Using the Airborne Snow Observatory to Assess Remotely Sensed Snowfall Products in the California Sierra Nevada Water Resour. Res. $547331-46$

- Behrangi A, Gardner A, Reager J T, Fisher J B, Yang D, Huffman G J and Adler R F 2018 b Using GRACE to estitmate snowfall accumulation and assess gauge undercatch corrections in high latitudes J. Clim. 31 8689-704

- Behrangi A, Singh A, Song Y and Panahi M 2019 Assessing Gauge Undercatch Correction in Arctic Basins in Light of GRACE Observations Geophys. Res. Lett. 46 11358-66

- Behrangi, A., S. Wong, K. Mallick, and J. B. Fisher (2014), On the net surface water exchange rate estimated from remote-sensing observation and reanalysis, International Journal of Remote Sensing, 35(6), 2170-2185, doi: 10.1080/01431161.2014.889866.

- Berkowitz B and Balberg I 1993 Percolation theory and its application to groundwater hydrology Water Resour. Res. 29 775-94 Online: https://doi.org/10.1029/92WR02707 
- Cao Y and Liang S 2018 Recent advances in driving mechanisms of the Arctic amplification: A review Kexue Tongbao/Chinese Sci. Bull. 63 2757-71

- Cauteruccio A, Colli M, Freda A, Stagnaro M and Lanza L G 2020 The role of free-stream turbulence in attenuating the wind updraft above the collector of precipitation gauges J. Atmos. Ocean. Technol. 37 103-13

- Chen J, Zhang X J and Brissette F P 2014 Assessing scale effects for statistically downscaling precipitation with GPCC model Int. J. Climatol. 34 708-27

- Colli M and Lanza L 2016 On the wind-induced undercatch in rainfall measurement using CFDbased simulations 1813798

- Colli M, Rasmussen R, Thériault J M, Lanza L G, Bruce Baker C and Kochendorfer J 2015 An improved trajectory model to evaluate the collection performance of snow gauges J. Appl. Meteorol. Climatol. 54 1826-36

- Colli M, Stagnaro M, Lanza L G, Rasmussen R O Y and Thériault J M 2020 Adjustments for wind-induced undercatch in snowfall measurements based on precipitation intensity $\mathrm{J}$. Hydrometeorol. 21 1039-50

- Colli M, Stagnaro M, Lanza L, Rasmussen R and Thériault J 2018 Using Snowfall Intensity to Improve the Correction of Wind-Induced Undercatch in Solid Precipitation Measurements Hydrol. Earth Syst. Sci. Discuss. 1-24

- Copernicus Climate Change Service (C3S), 2017: ERA5: Fifth generation of ECMWF atmospheric reanalyses of the global climate. Copernicus Climate Change Service Climate Data Store (CDS), Accessed 07 February 2019, doi: 10.24381/cds.e2161bac.

- Duffy G, King F, Bennartz R and Fletcher C G 2021 Seasonal estimates and uncertainties of snow accumulation from cloudsat precipitation retrievals Atmosphere (Basel). 12 1-14

- Ehsani M R, Arevalo J, Risanto C B, Javadian M, Devine C J, Arabzadeh A, Venegas-Quiñones H L, Dell'Oro A P and Behrangi A 2020: 2019-2020 Australia Fire and Its Relationship to Hydroclimatological and Vegetation Variabilities Water 123067 Online: https://www.mdpi.com/2073-4441/12/11/3067

- Ehsani M R, Behrangi A, Adhikari A, Song Y, Huffman G J, Adler R F, Bolvin D T and Nelkin E J 2021 Assessment of the Advanced Very High-Resolution Radiometer (AVHRR) for Snowfall Retrieval in High Latitudes Using CloudSat and Machine Learning J. Hydrometeorol. Online: https://journals.ametsoc.org/view/journals/hydr/aop/JHM-D-20-0240.1/JHM-D-20-0240.1.xml

- Fassnacht S R 2004 Estimating alter-shielded gauge snowfall undercatch, snowpack sublimation, and blowing snow transport at six sites in the coterminous USA Hydrol. Process. 18 3481-92

- Fiser O and Wilfert O 2009 Novel processing of Tipping-bucket rain gauge records Atmos. Res. 92 283-8 Online: http://dx.doi.org/10.1016/j.atmosres.2009.01.008

- Førland E J and Hanssen-Bauer I 2000 Increased precipitation in the Norwegian Arctic: True or false? Clim. Change 46 485-509

- Fuchs T, Rapp J, Rubel F and Rudolf B 2001 Correction of synoptic precipitation observations due to systematic measuring errors with special regard to precipitation phases Phys. Chem. Earth, Part B Hydrol. Ocean. Atmos. 26 689-93

- Goodison B, Louie P Y T and Yang D 1998 WMO solid precipitation measurement intercomparison Final Rep. 318

- Groisman P Y and Legates D R 1994 The accuracy of United States precipitation data Bull. - Am. Meteorol. Soc. 75 215-27 
- Grossi G, Lendvai A, Peretti G and Ranzi R 2017 Snow precipitation measured by gauges: Systematic error estimation and data series correction in the central Italian Alps Water (Switzerland) 9 1-14

- Hirabayashi Y, Kanae S, Motoya K, Masuda K and Döll P 2008 A 59-year (1948-2006) global meteorological forcing data set for land surface models. Part II: Global snowfall estimation Hydrol. Res. Lett. 2 65-9

- Huffman G J, Bolvin D T, Braithwaite D, Hsu K-L, Joyce R J, Kidd C, Nelkin E J, Sorooshian S, Stocker E F, Tan J, Wolff D B and Xie P 2020 Integrated Multi-satellite Retrievals for the Global Precipitation Measurement (GPM) Mission (IMERG) 343-53

- Huffman G. J., Adler R. F., Behrangi A., Bolvin D. T., Nelkin E., Song Y. 2020. Algorithm Theoretical Basis Document (ATBD) for Global Precipitation Climatology Project Version 3.1 Precipitation Data. URL: https://docserver.gesdisc.eosdis.nasa.gov/public/project/MEaSUREs/GPCP/GPCP ATBD V3.1. pdf

- Jimeno-Sáez P, Pulido-Velazquez D, Collados-Lara A J, Pardo-Igúzquiza E, Senent-Aparicio J and Baena-Ruiz L 2020 A preliminary assessment of the "undercatching" and the precipitation pattern in an alpine basin Water (Switzerland) 12 1-21

- Kidd C, Bauer P, Turk J, Huffman G J, Joyce R, Hsu K L and Braithwaite D 2012 Intercomparison of high-resolution precipitation products over Northwest Europe $\mathrm{J}$. Hydrometeorol. 13 67-83

- Kirschbaum D B, Huffman G J, Adler R F, Braun S, Garrett K, Jones E, McNally A, SkofronickJackson G, Stocker E, Wu H and Zaitchik B F 2017 NASA'S remotely sensed precipitation: A reservoir for applications users Bull. Am. Meteorol. Soc. 98 1169-84

- Kochendorfer J, Earle M E, Hodyss D, Reverdin A, Roulet Y A, Nitu R, Rasmussen R, Landolt S, Buisán S and Laine T 2020 Undercatch adjustments for tipping-bucket gauge measurements of solid precipitation J. Hydrometeorol. 21 1193-205

- Kochendorfer J, Nitu R, Wolff M, Mekis E, Rasmussen R, Baker B, Earle M E, Reverdin A, Wong K, Smith C D, Yang D, Roulet Y A, Buisan S, Laine T, Lee G, Aceituno J L C, Alastrué J, Isaksen K, Meyers T, Brækkan R, Landolt S, Jachcik A and Poikonen A 2017 Analysis of singleAlter-shielded and unshielded measurements of mixed and solid precipitation from WMO-SPICE Hydrol. Earth Syst. Sci. 21 3525-42

- Koehler G 2019 Snow gauge undercatch and its effect on the hydrogen and oxygen stable isotopic composition of precipitation. Isotopes Environ. Health Stud. 55 404-18

- Kucera P A, Ebert E E, Turk F J, Levizzani V, Kirschbaum D, Tapiador F J, Loew A and Borsche M 2013 Precipitation from space: Advancing earth system science Bull. Am. Meteorol. Soc. 94 365-75

- Legates D R 1995 Global and terrestrial precipitation: A comparative assessment of existing climatologies Int. J. Climatol. 15 237-58

- Legates D R and Bogart T A 2009 Estimating the proportion of monthly precipitation that falls in solid form J. Hydrometeorol. 10 1299-306

- Legates D R and Willmott C J 1990 Gauge-Corrected, Global Precipitation Int. J. 10

- Levizzani V, Laviola S and Cattani E 2011 Detection and measurement of snowfall from space Remote Sens. 3 145-66

- Liu Y, Li F, Hao W, Barriot J P and Wang Y 2019a Evaluation of synoptic snowfall on the Antarctic Ice Sheet based on CloudSat, in-situ observations and atmospheric reanalysis datasets Remote Sens. 11 
- Liu Y, Zhang P, Nie L, Xu J, Lu X and Li S 2019b Exploration of the snow ablation process in the semiarid region in China by combining site-based measurements and the Utah energy balance model-A case study of the Manas River Basin Water (Switzerland) 11

- Masuda M, Yatagai A, Kamiguchi K and Tanaka K 2019 Daily Adjustment for Wind-Induced Precipitation Undercatch of Daily Gridded Precipitation in Japan Earth Sp. Sci. 6 1469-79

- Mekonnen G B, Matula S, Doležal F and Fišák J 2015 Adjustment to rainfall measurement undercatch with a tipping-bucket rain gauge using ground-level manual gauges Meteorol. Atmos. Phys. 127 241-56

- Milani L and Wood N B 2021 Biases in CloudSat Falling Snow Estimates Resulting from Daylight-Only Operations 1-13

- Nicholson S E, Some B, McCollum J, Nelkin E, Klotter D, Berte Y, Diallo B M, Gaye I, Kpabeba G, Ndiaye O, Noukpozounkou J N, Tanu M M, Thiam A, Toure A A and Traore A K 2003 Validation of TRMM and other rainfall estimates with a high-density gauge dataset for West Africa. Part I: Validation of GPCC rainfall product and Pre-TRMM satellite and blended products J. Appl. Meteorol. 42 1337-54

- Panahi, M., and A. Behrangi (2020), Comparative Analysis of Snowfall Accumulation and Gauge Undercatch Correction Factors from Diverse Data Sets: In Situ, Satellite, and Reanalysis, AsiaPacific Journal of Atmospheric Sciences, 56(4), 615-628, doi: 10.1007/s13143-019-00161-6.

- Pierre A, Jutras S, Smith C, Kochendorfer J, Fortin V and Anctil F 2019 Evaluation of catch efficiency transfer functions for unshielded and single-alter-shielded solid precipitation measurements J. Atmos. Ocean. Technol. 36 865-81

- Pollock M D, O’Donnell G, Quinn P, Dutton M, Black A, Wilkinson M E, Colli M, Stagnaro M, Lanza L G, Lewis E, Kilsby C G and O’Connell P E 2018 Quantifying and Mitigating WindInduced Undercatch in Rainfall Measurements Water Resour. Res. 54 3863-75

- Prakash S, Gairola R M and Mitra A K 2015 Comparison of large-scale global land precipitation from multisatellite and reanalysis products with gauge-based GPCC data sets Theor. Appl. Climatol. 121 303-17

- Prakash S, Mahesh C and Gairola R M 2011 Large-scale precipitation estimation using Kalpana-1 IR measurements and its validation using GPCP and GPCC data Theor. Appl. Climatol. 106 28393

- Rasmussen R, Baker B, Kochendorfer J, Meyers T, Landolt S, Fischer A P, Black J, Thériault J M, Kucera P, Gochis D, Smith C, Nitu R, Hall M, Ikeda K and Gutmann E 2012 How well are we measuring snow: The NOAA/FAA/NCAR winter precipitation test bed Bull. Am. Meteorol. Soc. 93 811-29

- Raziei T, Bordi I and Pereira L S 2011 An Application of GPCC and NCEP/NCAR Datasets for Drought Variability Analysis in Iran Water Resour. Manag. 25 1075-86

- Raziei T, Bordi I, Pereira L S and Sutera A 2010 Space-time variability of hydrological drought and wetness in Iran using NCEP/NCAR and GPCC datasets Hydrol. Earth Syst. Sci. 14 1919-30

- Raziei T, Martins D S, Bordi I, Santos J F, Portela M M, Pereira L S and Sutera A 2015 SPI Modes of Drought Spatial and Temporal Variability in Portugal: Comparing Observations, PT02 and GPCC Gridded Datasets Water Resour. Manag. 29 487-504

- Rodell M, Beaudoing H K, L'Ecuyer T S, Olson W S, Famiglietti J S, Houser P R, Adler R, Bosilovich M G, Clayson C A, Chambers D, Clark E, Fetzer E J, Gao X, Gu G, Hilburn K, Huffman G J, Lettenmaier D P, Liu W T, Robertson F R, Schlosser C A, Sheffield J and Wood E F 2015 The observed state of the water cycle in the early twenty-first century J. Clim. 28 8289318 
- Rodell M, Chao B F, Au A Y, Kimball J S and McDonald K C 2005 Global biomass variation and its geodynamic effects: 1982-98 Earth Interact. 9

- Rodell M, Houser P R, Jambor U, Gottschalck J, Mitchell K, Meng C J, Arsenault K, Cosgrove B, Radakovich J, Bosilovich M, Entin J K, Walker J P, Lohmann D and Toll D 2004 The Global Land Data Assimilation System Bull. Am. Meteorol. Soc. 85 381-94

- Rubel F and Hantel M 1999 Correction of daily rain gauge measurements in the Baltic Sea Drainage Basin Nord. Hydrol. 30 191-208

- Rubel F and Hantel M 2001a BALTEX 1/6-degree daily precipitation climatology 1996-1998 Meteorol. Atmos. Phys. 77 155-66

- Rubel F and Hantel M 2001b BALTEX 1/6-degree daily precipitation climatology 1996-1998 Meteorol. Atmos. Phys. 77 155-66

- Rubel F, Fuchs T, Rudolf B and Ungersb M Bias correction of global daily rain gauge measurements Current status : printed Offset requests to : Bias correction of global daily rain gauge measurements

- Rubel F, Ungersböck M, Skomorowski P, Auer I, Rudolf B and Fuchs T 2000 On the Correction of Systematic Rain Gauge Measurement Errors Vet. Med. 63004-63004

- Sarmadi F and Shokoohi A 2015 Regionalizing precipitation in Iran using GPCC gridded data via multivariate analysis and L-moment methods Theor. Appl. Climatol. 122 121-8

- Schneider U, Becker A, Finger P, Meyer-Christoffer A, Ziese M and Rudolf B 2014 GPCC's new land surface precipitation climatology based on quality-controlled in situ data and its role in quantifying the global water cycle Theor. Appl. Climatol. 115 15-40

- Schneider, Udo; Becker, Andreas; Finger, Peter; Meyer-Christoffer, Anja; Ziese, Markus (2018): GPCC Monitoring Product: Near Real-Time Monthly Land-Surface Precipitation from RainGauges based on SYNOP and CLIMAT data. DOI: 10.5676/DWD_GPCC/MP_M_V6_100

- Schneider, Udo; Becker, Andreas; Finger, Peter; Rustemeier Elke; Ziese, Markus (2020): GPCC Monitoring Product: Near Real-Time Monthly Land-Surface Precipitation from Rain-Gauges based on SYNOP and CLIMAT data. DOI: 10.5676/DWD_GPCC/MP_M_V2020_100;

- Sevruk B 1987 Point Precipitation Measurements: Why Are They Not Corrected? IAHS Publ. (International Assoc. Hydrol. Sci. 477-86

- Sevruk B and Klemm S 1989 Catalogue of National Standard Precipitation Gauges World Meteorol. Organ. 3950

- Sevruk B, Ondrás M and Chvíla B 2009 The WMO precipitation measurement intercomparisons Atmos. Res. 92 376-80 Online: http://dx.doi.org/10.1016/j.atmosres.2009.01.016

- Skofronick-Jackson G, Hudak D, Petersen W, Nesbitt S W, Chandrasekar V, Durden S, Gleicher K J, Huang G J, Joe P, Kollias P, Reed K A, Schwhwaller M R, Stewart R, Tanelli S, Tokay A, Wang J R and Wolde M 2015 Global precipitation measurement cold season precipitation experiment (GCPEX): For measurement's sake, let it snow Bull. Am. Meteorol. Soc. 96 1719-41

- Smith C D, Ross A, Kochendorfer J, Earle M E, Wolff M, Buisán S, Roulet Y A and Laine T 2020 Evaluation of the WMO Solid Precipitation Intercomparison Experiment (SPICE) transfer functions for adjusting the wind bias in solid precipitation measurements Hydrol. Earth Syst. Sci. 24 4025-43

- Stephens G L, Li J, Wild M, Clayson C A, Loeb N, Kato S, L’Ecuyer T, Stackhouse P W, Lebsock M and Andrews T 2012 An update on Earth's energy balance in light of the latest global observations Nat. Geosci. 5 691-6

- Strangeways I 2006 Precipitation (Cambridge: Cambridge University Press) Online: http://ebooks.cambridge.org/ref/id/CBO9780511535772 
- Sugiura K, Yang D and Ohata T 2003 Systematic error aspects of gauge-measured solid precipitation in the Arctic, Barrow, Alaska Geophys. Res. Lett. 30 10-3

- Sun Q, Miao C, Duan Q, Ashouri H, Sorooshian S and Hsu K L 2018 A Review of Global Precipitation Data Sets: Data Sources, Estimation, and Intercomparisons Rev. Geophys. 56 79107

- Sypka P 2019 Dynamic real-time volumetric correction for tipping-bucket rain gauges Agric. For. Meteorol. 271 158-67 Online: https://doi.org/10.1016/j.agrformet.2019.02.044

- Tapiador F J, Turk F J, Petersen W, Hou A Y, García-Ortega E, Machado L A T, Angelis C F, Salio P, Kidd C, Huffman G J and de Castro M 2012 Global precipitation measurement: Methods, datasets and applications Atmos. Res. 104-105 70-97 Online: http://dx.doi.org/10.1016/j.atmosres.2011.10.021

- TRENBERTH K E 1973 Global Model of the General Circulation Of the Atmosphere Below 75 Kilometers With an Annual Heating Cycle Mon. Weather Rev. 101 287-305

- Trenberth K E, Fasullo J T and Kiehl J 2009 Earth's global energy budget Bull. Am. Meteorol. Soc. $90311-23$

- Ungersböck M, Rubel F, Fuchs T and Rudolf B 2001 Bias correction of global daily rain gauge measurements Phys. Chem. Earth, Part B Hydrol. Ocean. Atmos. 26 411-4

- Vahedizade S, Ebtehaj A, You Y, Ringerud S E and Turk F J 2021 Passive Microwave Signatures and Retrieval of High-Latitude Snowfall Over Open Oceans and Sea Ice: Insights From Coincidences of GPM and CloudSat Satellites IEEE Trans. Geosci. Remote Sens. 1-13 Online: https://ieeexplore.ieee.org/document/9411720/

- Wang G, Zhang P, Liang L and Zhang S 2017a Evaluation of precipitation from CMORPH, GPCP-2, TRMM 3B43, GPCC, and ITPCAS with ground-based measurements in the QinlingDaba Mountains, China PLoS One 12 1-23

- Wang X L, Xu H, Qian B, Feng Y and Mekis E 2017b Adjusted Daily Rainfall and Snowfall Data for Canada Atmos. - Ocean 55 155-68

- Wei L, Jiang S, Ren L, Yuan F and Zhang L 2019 Performance of two long-term satellite-based and GPCC 8.0 precipitation products for drought monitoring over the Yellow River Basin in China Sustain. 11

- Yang D, Goodison B E, Metcalfe J R, Louie P, Leavesley G, Emerson D, Hanson C L, Golubev V S, Elomaa E, Gunther T, Pangburn T, Kang E and Milkovic J 1999a Quantification of precipitation measurement discontinuity induced by wind shields on national gauges Water Resour. Res. 35 491-508

- Yang D, Goodison B, Metcalfe J, Louie P, Elomaa E, Hanson C, Golubev V, Gunther T, Milkovic J and Lapin M 2001 Compatibility evaluation of national precipitation gage measurements J. Geophys. Res. Atmos. 106 1481-91

- Yang D, Goodison B, Service A E, Gunther T, Golubev V and Sevruk B 1999b Wind-induced Precipitation Undercatch of the Hellmann Gauges In 1985 the WMO initiated the Solid Precipitation Measurement Intercomparison ( WMOICIMO 1985). The goal of this project was to assess national methods of $57-80$

- Yang D, Kane D L, Hinzman L D, Goodison B E, Metcalfe J R, Louie P Y T, Leavesley G H, Emerson D G and Hanson C L 2000 An evaluation of the Wyoming gauge system for snowfall measurement Water Resour. Res. 36 2665-77

- Yang D, Kane D, Zhang Z, Legates D and Goodison B 2005 Bias corrections of long-term (19732004) daily precipitation data over the northern regions Geophys. Res. Lett. 32 1-5 
- Yu K, Li Y, Jin T, Chang X, Wang Q and Li J 2020 Gnss-r-based snow water equivalent estimation with empirical modeling and enhanced snr-based snow depth estimation Remote Sens. $121-20$

- Ziese, Markus; Rauthe-Schöch, Armin; Becker, Andreas; Finger, Peter; Meyer-Christoffer, Anja; Schneider, Udo (2018): GPCC Full Data Daily Version.2018 at 1.0 : Daily Land-Surface Precipitation from Rain-Gauges built on GTS-based and Historic Data. DOI: 10.5676/DWD_GPCC/FD_D_V2018_100

- Ziese, Markus; Rauthe-Schöch, Armin; Becker, Andreas; Finger, Peter; Rustemeier, Elke; Schneider, Udo (2020): GPCC Full Data Daily Version 2020 at $1.0^{\circ}$ : Daily Land-Surface Precipitation from Rain-Gauges built on GTS-based and Historic Data. DOI: 10.5676/DWD_GPCC/FD_D_V2020_100 


\section{Tables \& Figures}

Table 1- Annual and seasonal global mean precipitation rates in $\mathrm{mm}$ /day over land from GPCC V2020, GPCC-L, GPCC-F, and GPCC V2018. The analysis does not include Antarctica because GPCC and CF-L do not cover Antarctica. The percent values in parentheses display the percent increase of total precipitation as compared to GPCC V2020 that is not corrected for undercatch.

\begin{tabular}{|l|c|c|c|c|c|}
\hline & Annual & DJF & MAM & JJA & SON \\
\hline GPCC V2020 & $\mathbf{2 . 5 1}$ & $\mathbf{2 . 5 5}$ & $\mathbf{2 . 5 0}$ & $\mathbf{2 . 5 9}$ & $\mathbf{2 . 4 1}$ \\
\hline GPCC-L & $\mathbf{2 . 7 5}$ & $\mathbf{2 . 8 1}$ & $\mathbf{2 . 7 4}$ & $\mathbf{2 . 8 0}$ & $\mathbf{2 . 6 5}$ \\
\hline & $(+9.5 \%)$ & $(+10.3 \%)$ & $(+9.8 \%)$ & $(+8.0 \%)$ & $(+10.1 \%)$ \\
\hline GPCC-F & $\mathbf{2 . 6 7}$ & $\mathbf{2 . 7 1}$ & $\mathbf{2 . 6 6}$ & $\mathbf{2 . 7 4}$ & $\mathbf{2 . 5 6}$ \\
\hline (+6.3\%) & $(+6.7 \%)$ & $(+6.4 \%)$ & $(+5.8 \%)$ & $(+6.4 \%)$ \\
\hline GPCC V2018 & $\mathbf{2 . 5 2}$ & $\mathbf{2 . 5 5}$ & $\mathbf{2 . 5 0}$ & $\mathbf{2 . 6 0}$ & $\mathbf{2 . 4 1}$ \\
\hline & $(+0.1 \%)$ & $(+0.2 \%)$ & $(+0.0 \%)$ & $(+0.1 \%)$ & $(+0.1 \%)$ \\
\hline
\end{tabular}



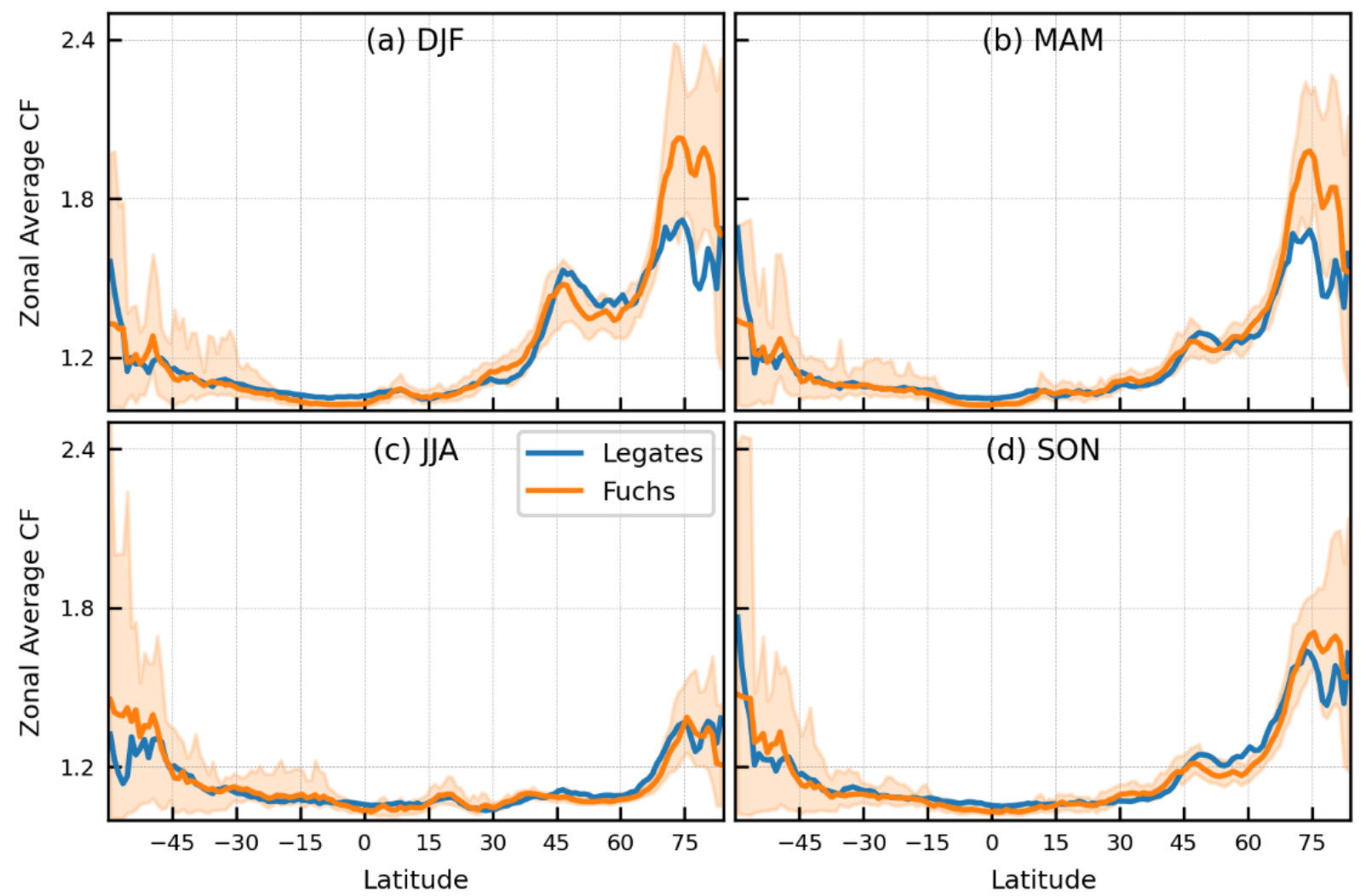

Figure 1: Zonal plots of seasonal CF-L and CF-F using 38 years (1982-2019) of monthly CF-F data: (a) winter (DJF), (b) spring (MAM), (c) summer (JJA), and (d) fall (SON). Zonal averages are calculated at 1degree zonal bins. Panels (e) and (f) show zonal plots of seasonal relative differences between mean CF-F and CF-L and zonal number of 1-degree grids over land, respectively. 

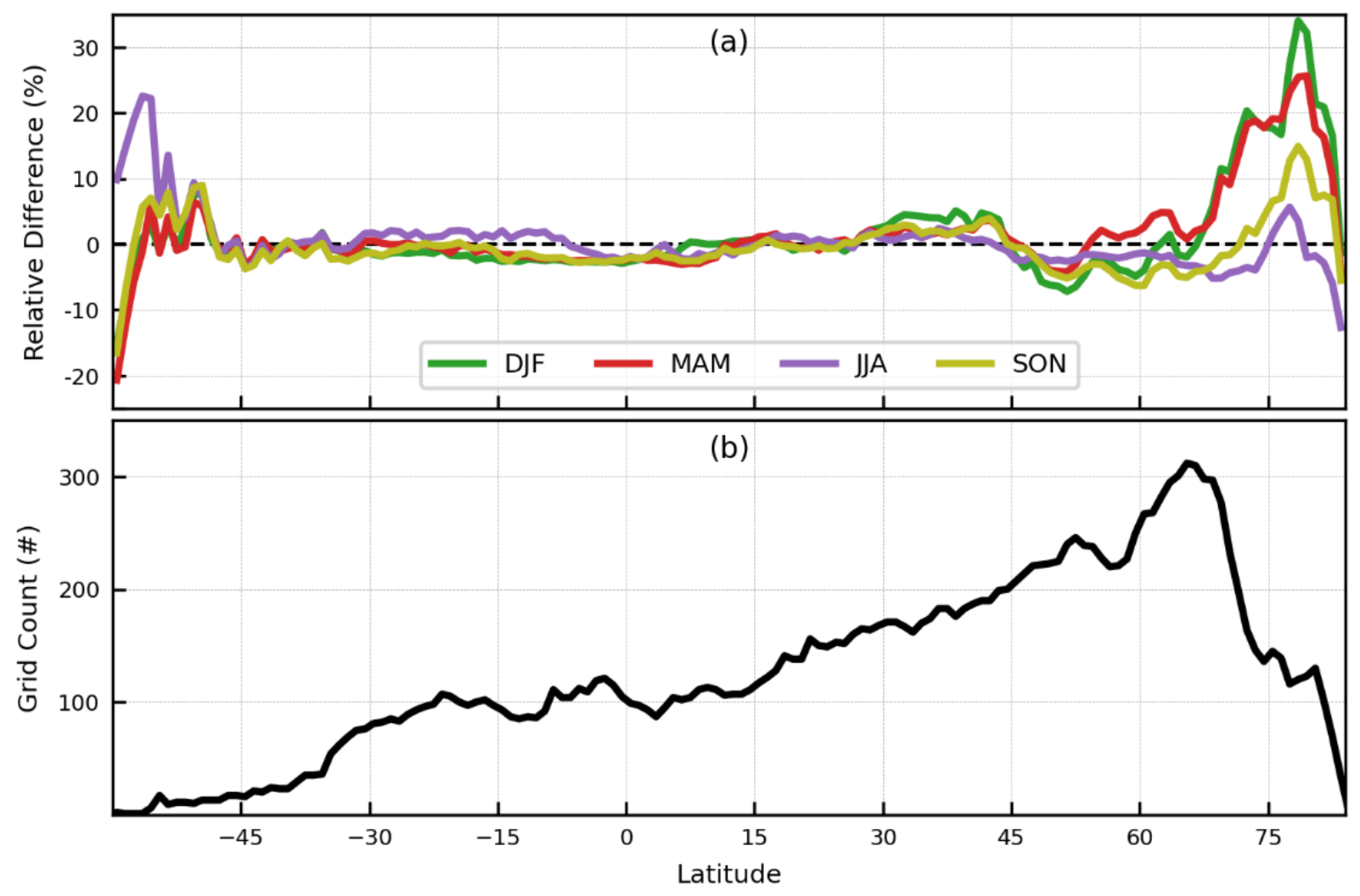

Figure 2: Seasonal relative differences between zonal CF-F and CF-L (a) and zonal number of 1-degree grids over land (2). 


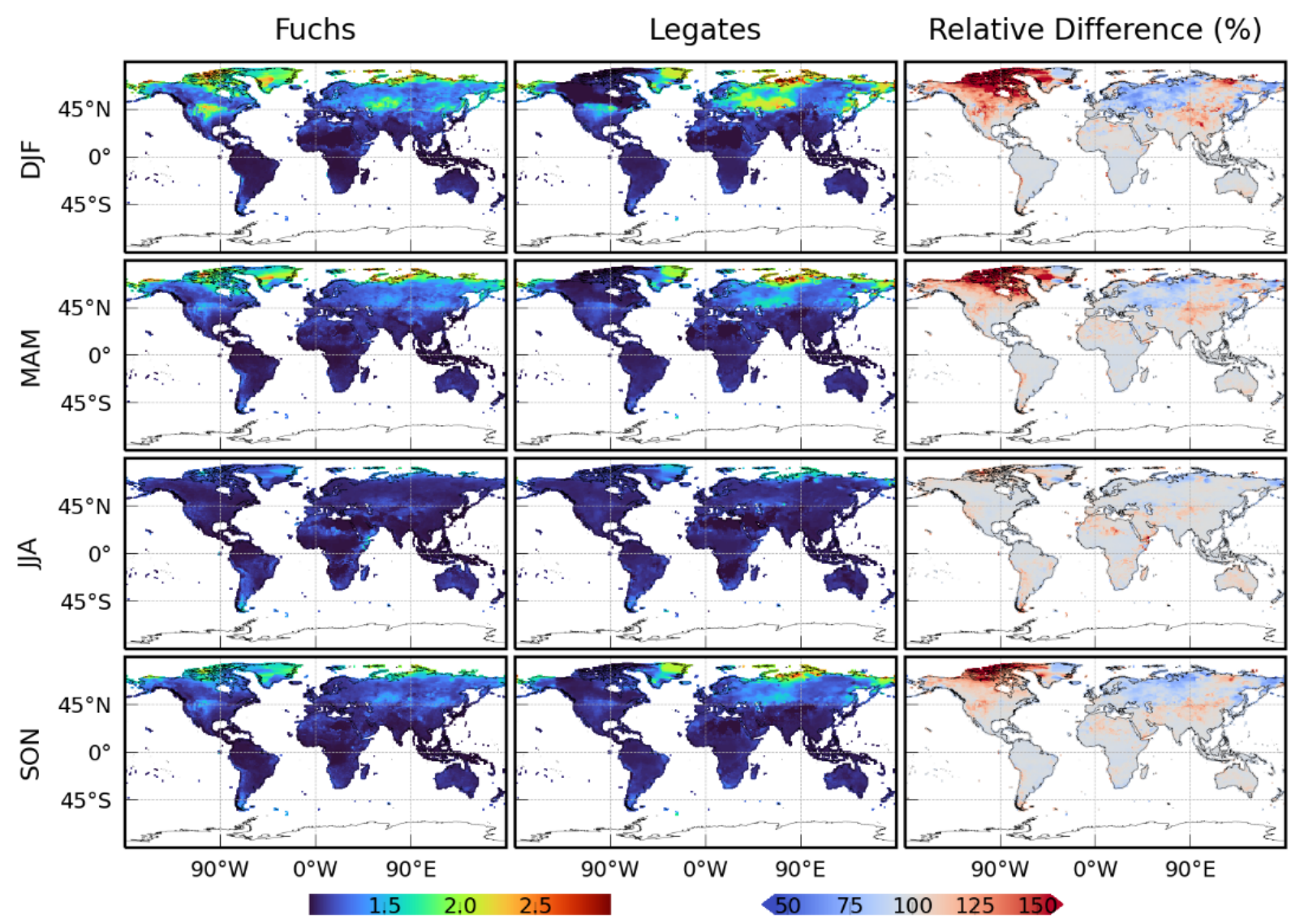

Figure 3: Seasonal maps of CF-F (left column) and CF-L (middle column), and relative differences between the two (i.e., $\frac{100 \times C F-F}{C F-L}$, right column) calculated from monthly CF-L and 38 years (1982-2019) of monthly CF-Fs. From top to bottom, rows show winter, spring, summer, and fall, respectively. The maps are produced at 1-degree spatial resolution. 


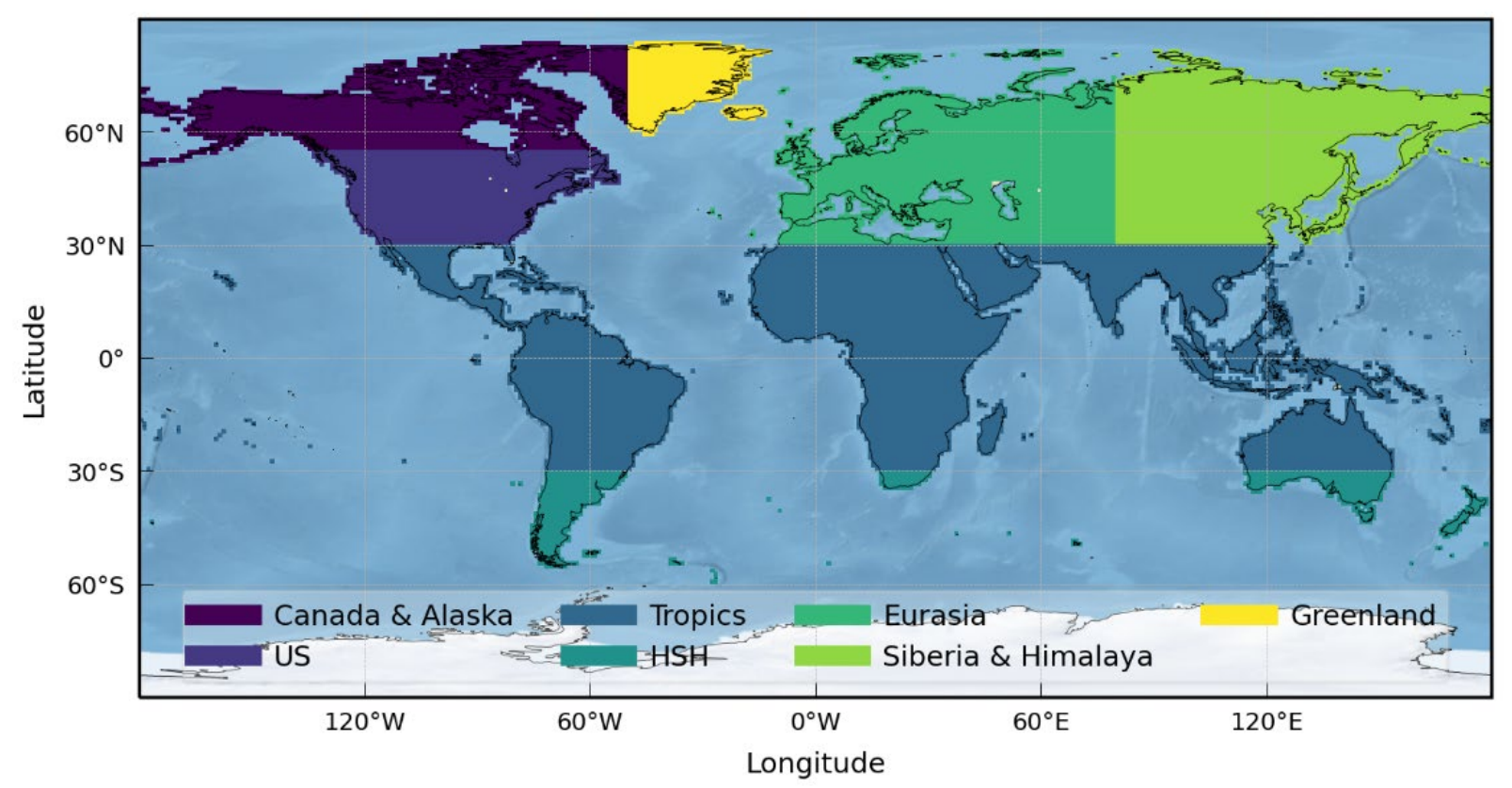

Figure 4: Regions defined to further investigate the impact of CFs on precipitation estimates. These regions include Canada and Alaska, the United States (US), Greenland, Tropics, Eurasia, Siberia and Himalaya, and higher latitudes in the Southern Hemisphere (HSH). 


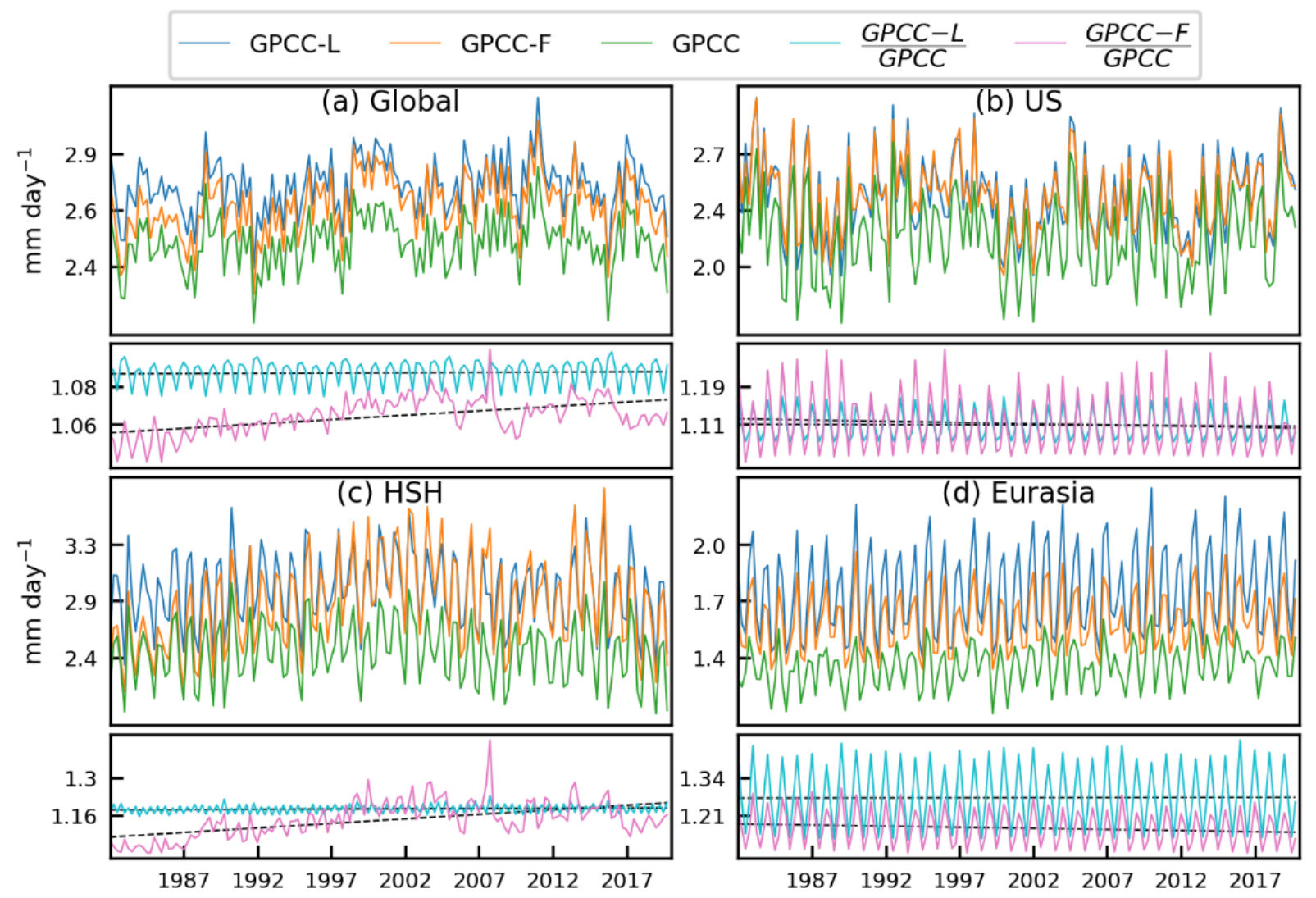

Figure 5: Seasonal time-series of mean monthly GPCC, GPCC-L, and GPCC-F for the global land, US, HSH, and Eurasia. Note that the time-series represents monthly mean values, but the reported unit is mm/day. Relative differences of GPCC-L and GPCC-F with respect to GPCC are also plotted in the bottom panel for each region. 

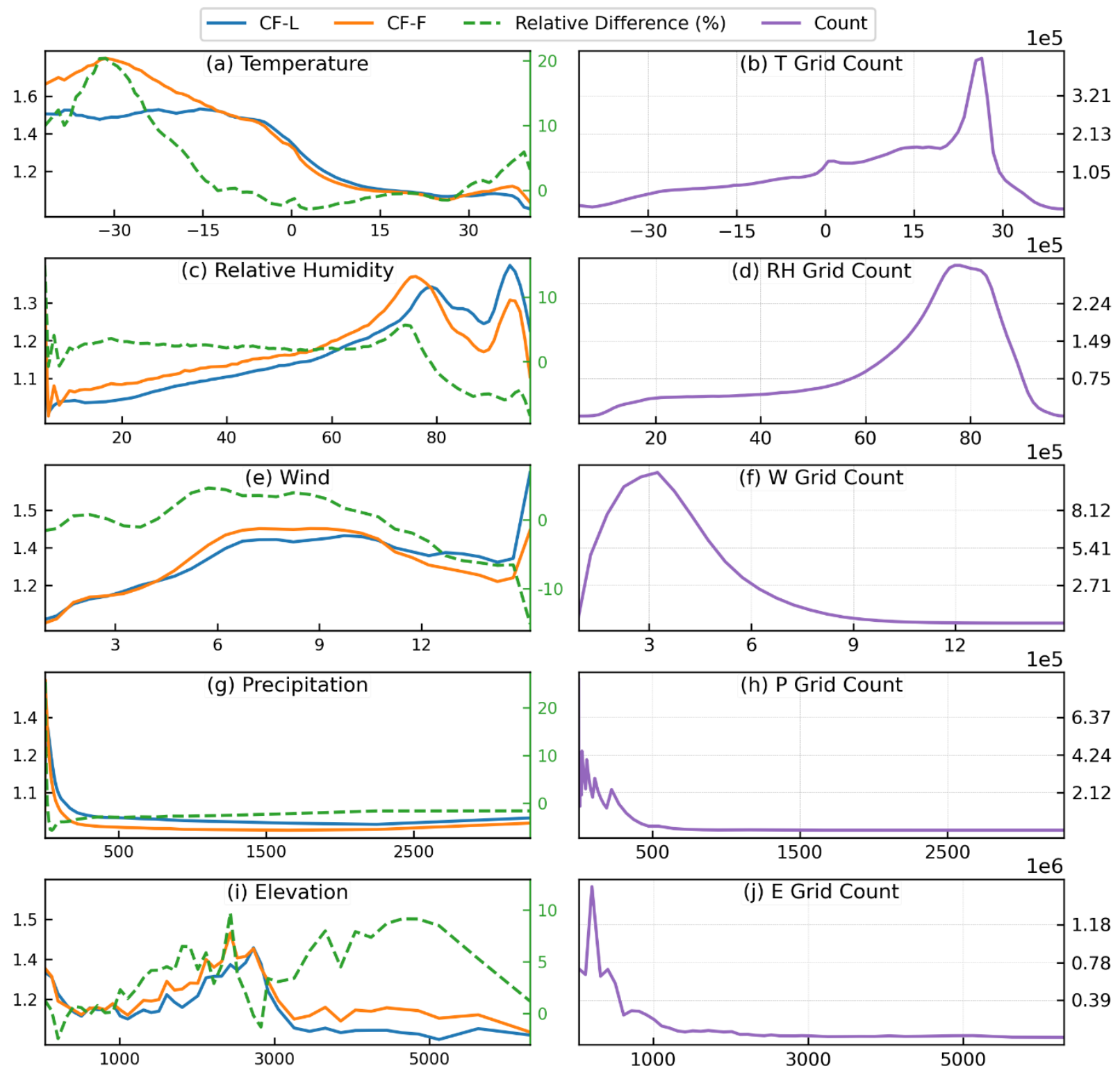

Figure 6: Comparison of CF-F and CF-L and their relative difference as a function of temperature in ${ }^{\circ} \mathrm{C}$ (T; panel a), relative humidity in \% (RH; panel b), wind speed in $\mathrm{m} \mathrm{s}^{-1}(\mathrm{~W}$; panel c), precipitation rate in $\mathrm{mm} \mathrm{day}^{-1}(\mathrm{P}$; panel d), and elevation in $\mathrm{m}$ (E; panel e). Number of samples in bins are also plotted in adjacent panels for each environmental variable. 

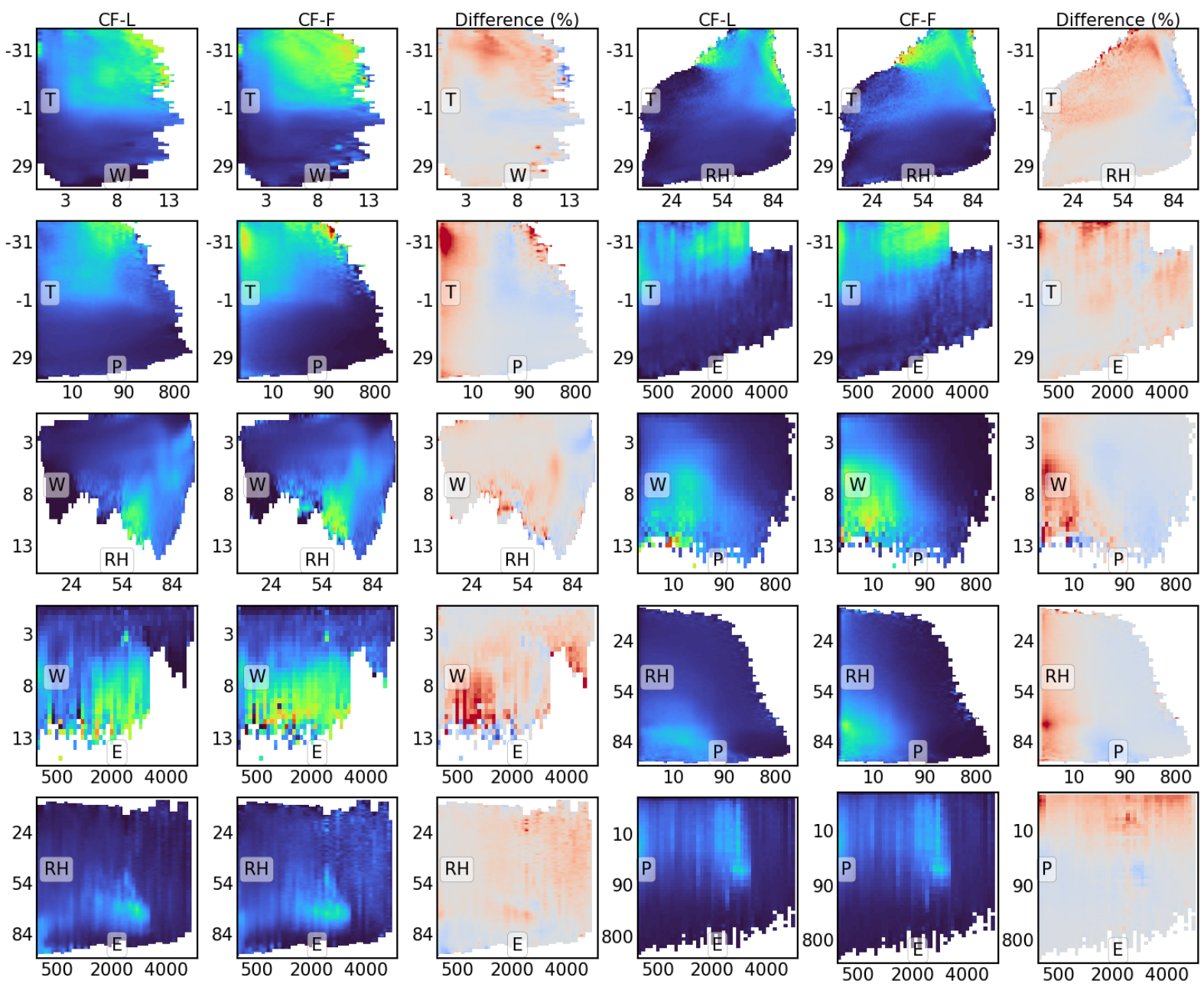

$\begin{array}{lll}1.5 & 2.0 & 2.5\end{array}$

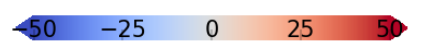

Figure 7: Mean CFs and their relative differences (i.e., $\frac{100 \times C F-F}{C F-L}$ ) as a function of joint environmental conditions. T, $\mathrm{P}, \mathrm{W}$, and $\mathrm{RH}$ represent $2 \mathrm{~m}$ temperature in ${ }^{\circ} \mathrm{C}$, and near surface precipitation in $\mathrm{mm} \mathrm{day}^{-1}$, wind in $\mathrm{m} \mathrm{s}^{-1}$, and relative humidity in $\%$, respectively. 


\section{Supplementary Figures}
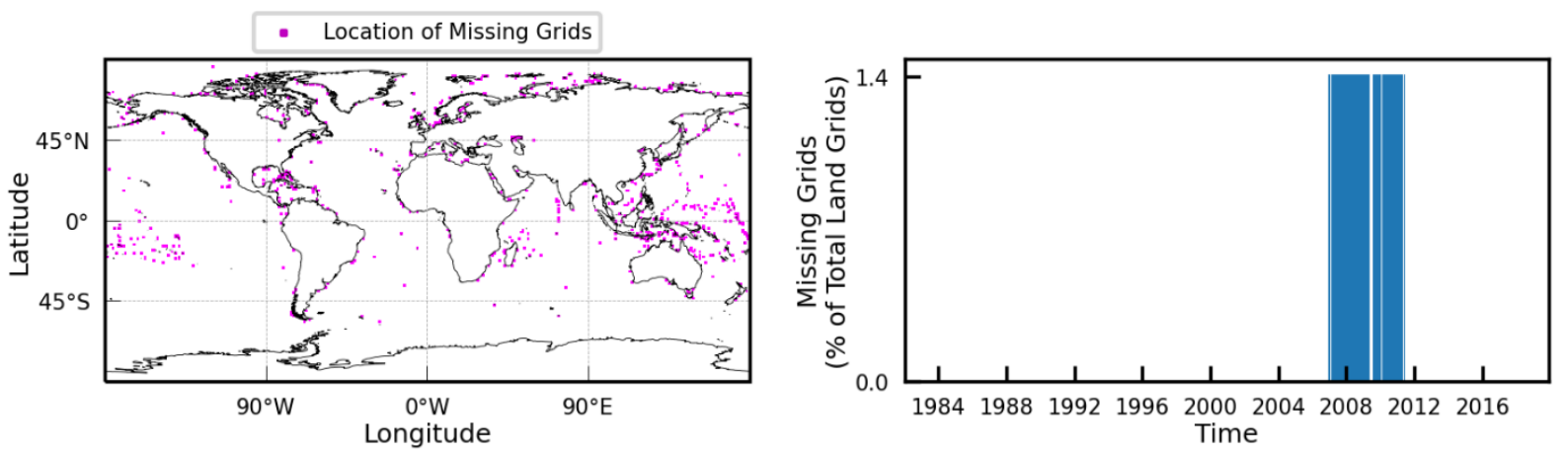

Figure S1: Time-series of missing values as a percentage of total land grids (right), and location of missing grids (left) for Fuchs CFs provided in the GPCC monthly Monitoring product. The missing values mainly occur between 2007 and 2011 and located in coastal regions or in islands. 


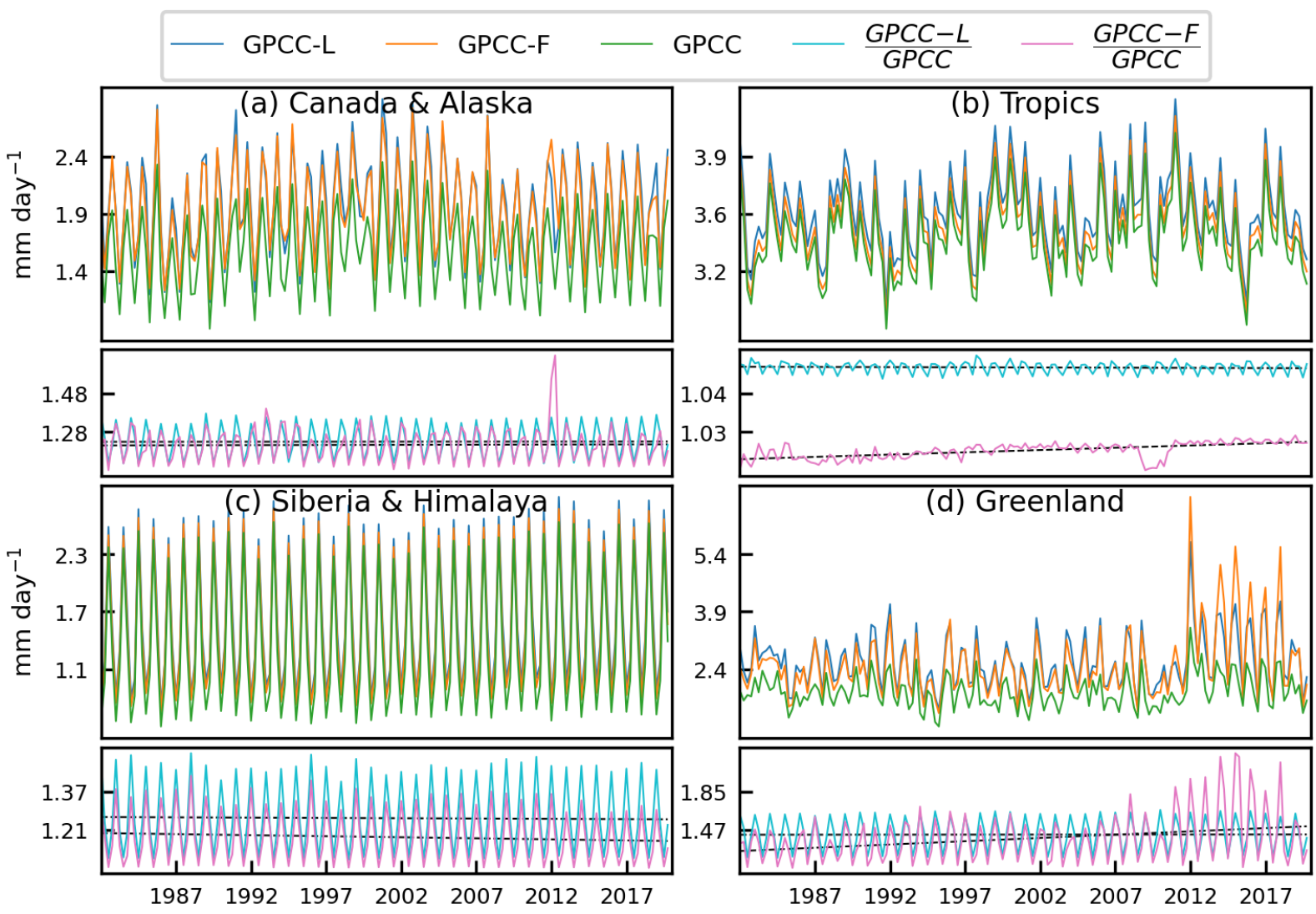

Figure S2: Seasonal time-series of mean monthly GPCC, GPCC-L, and GPCC-F for Canada \& Alaska, Tropics, Siberia and Himalaya, and Greenland. Note that the time-series represents monthly mean values, but the reported unit is $\mathrm{mm} /$ day. Relative differences of GPCC-L and GPCC-F with respect to GPCC are plotted in the bottom panel for each region. 


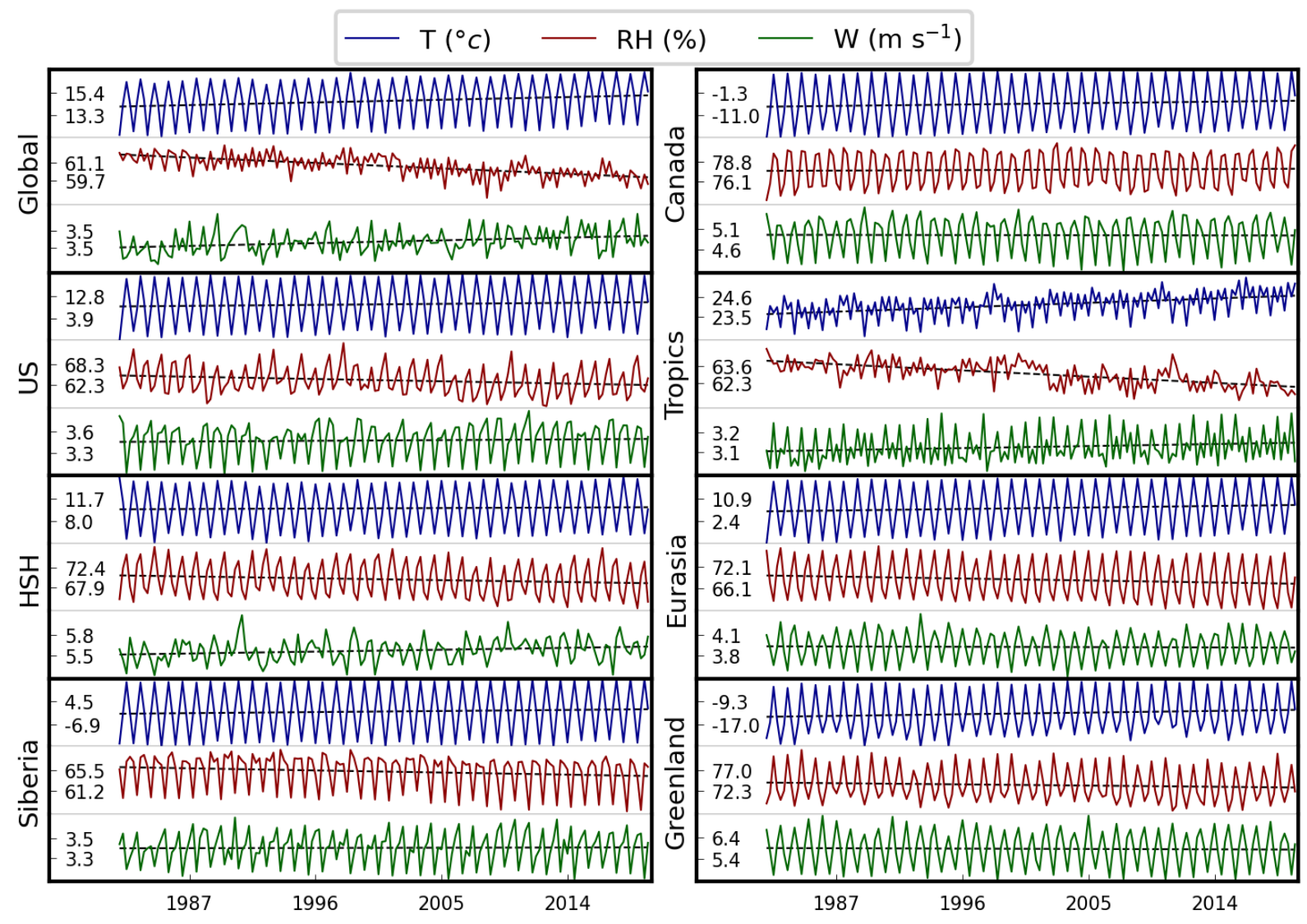

Figure S3: Seasonal values of global surface air temperature (T), relative humidity (RH), and wind speed (W) using ERA5 for different regions. Trendlines for each variable are also plotted. Note that sub-panels are separated with horizontal lines and numbers on the $y$-axis shows $1 / 3$ and $2 / 3$ of the range. 


\section{DJF}

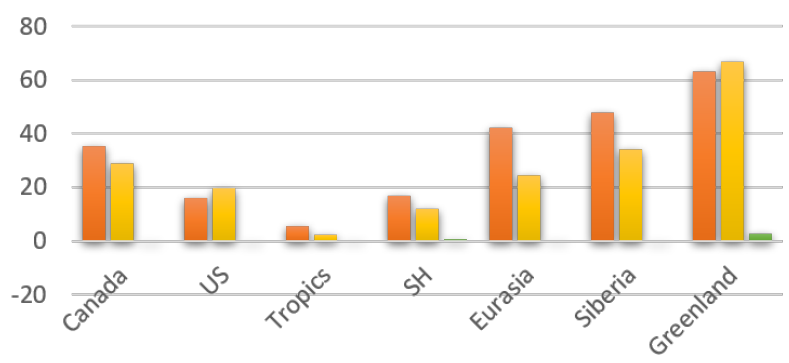

JJA

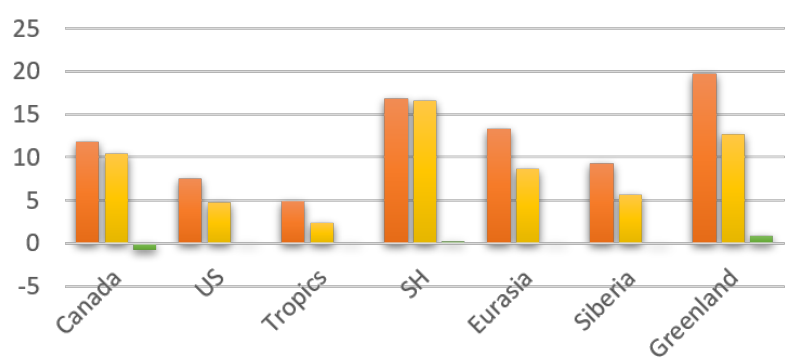

MAM

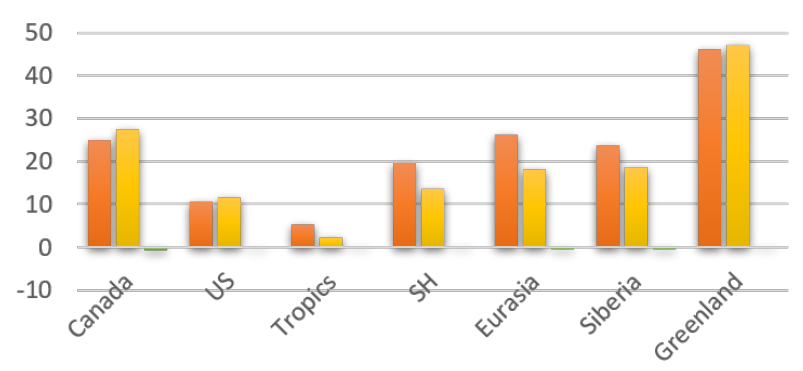

SON

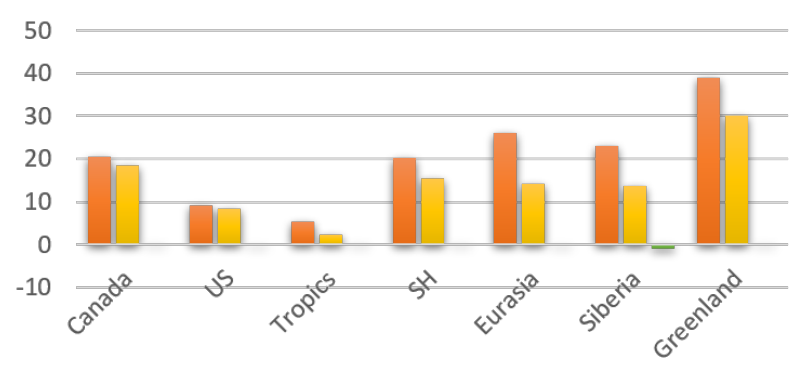

Annual

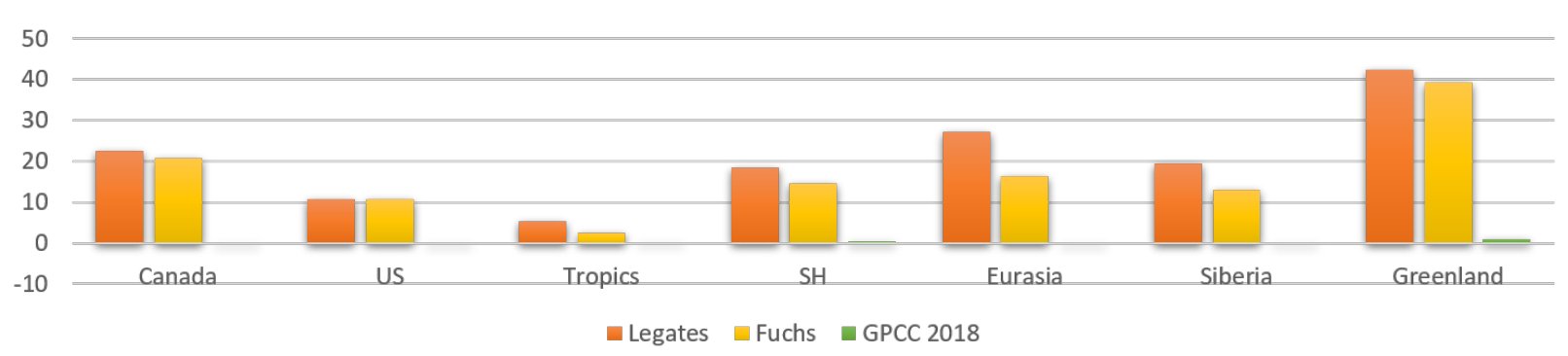

Figure S4: Percent change in measured precipitation amount compared to GPCC V2020 in each region for GPCC-F (red), GPCC-L (yellow) and GPCC V2018 (green). 